\title{
Formação continuada de professores de Ciências: uma análise em periódicos científicos
}

\author{
Continuing education of science teachers: an analysis in scientific \\ journals
}

Thaís Rios da Rocha ${ }^{1}$

Mara Elisa Fortes Braibante ${ }^{2}$

\section{Resumo}

Neste trabalho são apresentados os resultados de uma pesquisa bibliográfica realizada com o intuito de investigar de que modo os cursos de formação continuada de professores de Ciências da educação básica estão sendo organizados em âmbitos nacional e internacional. Foram selecionados dez periódicos para análise no período de 2006 a 2016, sendo 6 nacionais e 4 internacionais. Após uma leitura exploratória, analítica e interpretativa dos 68 artigos selecionados, surgiram categorias emergentes de acordo com as semelhanças dos assuntos abordados nos cursos de formação. Os artigos também foram analisados quanto à abrangência, tipo de formação, nível de atuação dos docentes participantes e tempo de duração dos cursos de formação. Dentre os resultados, constatamos que apenas 13 dos 68 artigos descrevem atividades de formação continuada realizadas para os professores de Ciências da educação básica, a nível fundamental e médio, o que evidencia a carência desse tipo de formação voltada para os professores da rede básica de ensino.

Palavras chave: formação continuada; professores de Ciências; educação básica.

\section{Abstract}

This work presents the results of a bibliographic research carried out in order to investigate how the continuing education courses for science teachers in basic education are organized at national and international levels. Ten journals were selected for analysis from 2006 to 2016, 6 national and 4 international. After an exploratory, analytical and interpretative reading of the 68 selected articles, emergent categories appeared according to the similarities of the subjects covered in the formation courses. The articles were also analyzed regarding the scope, type of formation, level of performance of the participating teachers and duration of the courses. Among the results, we found that only 13 of the 68 articles describe continuing education activities carried out for basic and secondary education science teachers, which highlights the lack of this type of formation for teachers in the basic education network.

Keywords: continuing education; science teachers; basic education.

\footnotetext{
${ }^{1}$ Universidade Federal de Santa Maria | thaisufsm@gmail.com

${ }^{2}$ Universidade Federal de Santa Maria | maraefb@gmail.com
} 


\section{Introdução}

A formação inicial e continuada de professores vem apresentando destaque nos documentos oficiais que regem a educação básica brasileira (BRASIL, 2015), bem como em debates e discussões em congressos, conferências e eventos na área de Ciências a nível mundial. Esse cenário mundial e brasileiro vem se modificando ao longo do tempo, sendo que as ações formativas passaram a ser tratadas como essenciais para a carreira docente (ANDRÉ, 2010; FORMOSINHO, 2009; MARCELO, 2009).

Nóvoa (1992, p.16) ressalta que "mais do que um lugar de aquisição de técnicas e de conhecimentos, a formação de professores é o momento-chave da socialização e da configuração profissional". Entretanto, o autor também destaca que não basta apenas um processo de acumulação de cursos, conhecimentos e técnicas, mas também deve haver um trabalho de reflexão crítica sobre as práticas desenvolvidas e uma (re)construção permanente da identidade pessoal. A partir desta reflexão é importante que o professor partilhe as suas experiências e saberes formando um processo interativo com o grupo de formação.

Acreditamos que os processos formativos docentes devem considerar, além de uma abordagem sobre como trabalhar os conhecimentos científicos da disciplina de estudo e utilizar as ferramentas e metodologias de ensino, é necessário levar em consideração os saberes docentes desses professores. Conforme Tardif (2014, p. 36), "pode-se definir o saber docente como um saber plural, formado pela amálgama, mais ou menos coerente, de saberes oriundos da formação profissional e de saberes disciplinares, curriculares e experienciais". Manfredo e Gonçalves (2020) consideram fundamentais as histórias de vida dos professores, carregadas de significados desde a fase pré-profissional de sua trajetória, cujos saberes vão se consolidando ao longo desse caminhar e que impactam decisões, atitudes e ações docentes.

Nesse sentido, a presente pesquisa caracterizada por um levantamento bibliográfico, teve por objetivo analisar de que forma estão sendo realizados os cursos de formação continuada para professores de Ciências da educação básica, a partir da análise de periódicos publicados em revistas nacionais e internacionais no período de 2006 a 2016. Os resultados obtidos forneceram subsídios para a elaboração e implementação de um curso de formação continuada com professores de Ciências da educação básica (ROCHA, 2018).

Como foco de investigação selecionamos artigos de periódicos que realizaram cursos de formação continuada com professores pertencentes à área de Ciências da Natureza e suas Tecnologias, a qual é integrada pelos componentes curriculares Química, Física e Biologia. Além disso, analisamos o enfoque dado em cada artigo com relação às contribuições para a formação dos docentes.

A partir de 1998 até o ano de 2006 surgiram diversos documentos oficiais com o intuito de orientar a educação básica brasileira, como os Parâmetros Curriculares Nacionais para o Ensino Médio (BRASIL, 2000) e as Orientações Curriculares para o Ensino Médio (BRASIL, 2006). Neste trabalho, buscamos analisar as publicações realizadas no período posterior a promulgação desses documentos oficiais até o ano de 2016. 


\section{Metodologia}

Esta revisão da literatura apresenta um caráter predominantemente qualitativo (BOGDAN; BIKLEN, 1994; GÜNTHER, 2006), pois não estamos interessados apenas na quantidade de publicações voltadas para a formação continuada de professores de Ciências, mas também analisar como estão sendo desenvolvidos esses processos formativos com vistas ao aprimoramento pessoal e profissional do professor e, consequentemente, benefícios para a rede básica de ensino. Além disso, este trabalho caracteriza-se como uma pesquisa bibliográfica (GIL, 2002). Segundo o autor, esse tipo de pesquisa permite uma análise mais ampla dos fenômenos se comparada a uma pesquisa direta sobre o assunto que se quer analisar.

Este levantamento bibliográfico foi estruturado com base nas etapas sugeridas por Gil (2002), sendo elas: 1) Escolha do tema; 2) Levantamento bibliográfico preliminar; 3) Formulação do problema; 4) Elaboração do plano provisório do assunto; 5) Busca das fontes; 6) Leitura do material; 7) Fichamento; 8) Organização lógica do assunto e 9) Redação do texto.

O item 1 refere-se à escolha do tema para a realização da pesquisa bibliográfica. Nesta etapa geralmente o tema escolhido é amplo, o que requer posteriormente um afunilamento com relação ao assunto a ser pesquisado. O item 2, "levantamento bibliográfico preliminar", é necessário para orientar quanto a formulação do problema. Esta etapa caracteriza-se como um estudo exploratório, o que proporciona uma familiarização com o tema escolhido e, consequentemente, uma delimitação do mesmo.

A formulação do problema - item 3, é o momento em que as ideias estão claras, assim como está delineado o que se pretende analisar a respeito do assunto escolhido. A quarta etapa, "elaboração do plano provisório do assunto", é a organização sistemática das etapas que constituem o levantamento bibliográfico. No item 5, "busca das fontes", são identificadas as fontes bibliográficas necessárias para o desenvolvimento da pesquisa. Com relação à leitura do material, item 6, a mesma deve ser realizada cuidadosamente, procurando identificar as informações e dados que são pertinentes para a pesquisa em questão.

O item 7, caracterizado como "fichamento", é o momento em que são registrados os tópicos principais de cada material bibliográfico, sendo realizada uma análise detalhada do mesmo. A organização lógica do assunto, item 8, refere-se à construção lógica das ideias buscando atender ao problema e aos objetivos da pesquisa. Por fim, no item 9, "redação do texto", é realizada uma sistematização das ideias para que se formule considerações a respeito do levantamento realizado. A seguir, serão descritas detalhadamente cada uma dessas etapas associadas ao levantamento bibliográfico realizado neste trabalho sobre a formação continuada de professores de Ciências da educação básica.

\section{Resultados e discussões}

\section{1) Escolha do tema}

Para iniciar o levantamento bibliográfico, o tema escolhido para ser investigado foi "formação continuada de professores de Ciências". Inicialmente não restringimos os trabalhos com relação ao nível de ensino de atuação dos professores, sendo que poderiam 
surgir trabalhos realizados com professores de Ciências do ensino fundamental e médio (área de Ciências da Natureza).

\section{2) Levantamento bibliográfico preliminar}

De acordo com o foco desta pesquisa, que é a investigação de artigos relacionados a formação continuada de professores de Ciências, buscou-se realizar o levantamento bibliográfico em periódicos voltados para esta área de estudo. Com o intuito de visualizar o cenário mundial da pesquisa em Educação em Ciências relacionada a formação continuada de professores, foram analisados artigos de periódicos nacionais e internacionais.

O Quadro 1 apresenta os 10 periódicos que serviram como base para a realização desta pesquisa bibliográfica, sendo encontrados 6 periódicos nacionais e 4 internacionais.

Quadro 1- Periódicos nacionais e internacionais analisados

\begin{tabular}{|c|c|}
\hline Periódicos nacionais & Qualis \\
\hline Ciência \& Educação (CE) & $\mathrm{A} 1$ \\
\hline Ensaio Pesquisa em Educação em Ciências (EPEC) & $\mathrm{A} 1$ \\
\hline Amazônia - Revista de Educação em Ciências e Matemáticas (AmazRECM) & $\mathrm{A} 2$ \\
\hline Investigações em Ensino de Ciências (IEC) & $\mathrm{A} 2$ \\
\hline Revista Acta Scientiae (RAS) & $\mathrm{A} 2$ \\
\hline Periódicos internacionais & $\mathrm{A} 2$ \\
\hline Enseñanza de las Ciencias (EnC) & $\mathrm{Qualis}$ \\
\hline Brasileira de Pesquisa em Educacaão em Ciências (RBPEC) & $\mathrm{A} 1$ \\
\hline Revista Eureka sobre Enseñanza y Divulgación de las Ciencias (REurEDC) & $\mathrm{A} 1$ \\
\hline Revista Electrónica de Investigación en Educación en Ciencias \\
(en línea) (REIEC) & $\mathrm{A} 2$ \\
\hline
\end{tabular}

Para realizar este levantamento bibliográfico preliminar pesquisamos no Portal de Periódicos da Coordenação de Aperfeiçoamento de Pessoal de Nível Superior (CAPES), os periódicos que fazem parte da área de Ensino, que totalizam 2962 periódicos nacionais e internacionais. Selecionamos os periódicos que possuem uma qualidade da produção intelectual dos programas de pós-graduação, conhecido como Qualis, A1 e A2, o que correspondeu a 337 periódicos.

Com o objetivo de delimitar a nossa pesquisa, dos 337 periódicos selecionamos 45 que apresentavam no nome da revista os seguintes termos: ciência(s); ciencias (termo em espanhol); science(s); scietiae (termo em latim). Ressaltamos que os periódicos relacionados a biociências, ciências geológicas, ciências da comunicação e ciências referente a área de engenharia, foram excluídos de nossa pesquisa. 
Dos 45 periódicos selecionados, realizamos uma busca mais detalhada analisando os seguintes itens:

a) Escopo dos periódicos: realizou-se uma visita no ambiente virtual de cada um dos periódicos, a fim de analisar quais os tipos de publicações que são de interesse da revista. Selecionamos aqueles periódicos que visam, preferencialmente, publicar trabalhos voltados para a educação básica e que contemplem a área de Ciências da Natureza.

b) Período de publicações: selecionamos apenas os periódicos que publicaram artigos no período de nosso interesse, 2006-2016. Revistas que iniciaram posteriormente a 2006, ou que não disponibilizam o acesso online às publicações nesse período, foram excluídas de nossa pesquisa.

c) Acesso as publicações: também consideramos um item de exclusão as revistas que não disponibilizam as suas publicações com acesso gratuito, ou disponibilizam em sua parcialidade.

d) Periódicos de diferentes áreas: não consideramos anais, resenhas, revistas de jornalismo científico e ciências voltadas para a área de agronomia, nutrição, geografia, entre outros.

Após essa análise detalhada foram selecionados os 6 periódicos nacionais e 4 internacionais para serem analisados, conforme está apresentado no Quadro 1.

\section{3) Formulação do problema}

A partir da escolha do tema geral deste levantamento bibliográfico, bem como a seleção dos periódicos a serem analisados em um período de publicação que compreende os anos de 2006 a 2016, temos o seguinte problema de investigação: "De que modo os cursos de formação continuada de professores de Ciências da educação básica estão sendo organizados em âmbitos nacional e internacional?". Para responder a este problema foi elaborado um plano provisório, descrito a seguir, que corresponde as palavras que foram pesquisadas na base de dados de cada periódico, além dos elementos que foram elencados para serem analisados em cada artigo.

\section{4) Elaboração do plano provisório do assunto}

O plano provisório do assunto a ser pesquisado caracteriza-se como a organização sistemática das etapas que constituem o levantamento bibliográfico. Para a busca das publicações nos periódicos selecionados para análise utilizamos a base de dados de cada uma das revistas, no período de 2006 a 2016, sendo pesquisadas as seguintes palavraschave:

Periódicos nacionais: formação continuada; continuada; curso.

Periódicos internacionais: formación del profesorado; formación continua; teacher training; formação continuada; curso.

Para a análise das revistas nacionais, pesquisamos cada uma das palavras-chave individualmente, bem como nos seguintes pares: continuada e curso; formação continuada e curso. Inicialmente colocamos no sistema de busca das revistas a palavra-chave "ciências", que é o foco deste levantamento bibliográfico, entretanto percebemos que muitos trabalhos utilizam termos mais abrangentes no título, palavras-chave e resumo, sendo esses os itens selecionados para a busca. Sendo assim, optamos por não utilizar a palavra "ciências" na busca, e sim realizar uma leitura inicial exploratória desse termo, enfocando 
também cursos de formação continuada de professores de Ciências para a "educação básica".

Com relação à pesquisa realizada nos periódicos internacionais, também pesquisamos as palavras-chave individualmente, além dos seguintes pares: formação continuada e curso; formación del profesorado e curso. É possível perceber que além dos termos pesquisados em espanhol, também utilizamos termos em português e inglês. Os periódicos Enseñanza de las Ciencias e Revista Eureka admitem a submissão de trabalhos escritos na língua espanhola e inglesa. Já os periódicos REEC e REIEC aceitam artigos escritos em espanhol, português, inglês, francês, entre outros. O levantamento realizado dos artigos selecionados nesta fase de busca será detalhado no tópico a seguir.

\section{5) Busca das fontes}

Com relação à pesquisa realizada na base de dados de cada periódico, a Tabela 1 apresenta o número total de artigos nacionais e internacionais que foram publicados no período de 2006 a 2016, bem como o número de artigos encontrados em cada um dos periódicos nesse período e a sua correspondente percentagem.

Tabela 1- Periódicos nacionais e internacionais e seu respectivo número de artigos selecionados para análise

\begin{tabular}{|c|c|c|c|c|}
\hline & Títulos & $\begin{array}{c}\text { Total de } \\
\text { publicações }\end{array}$ & $\begin{array}{l}\text { Número de } \\
\text { artigos } \\
\text { selecionados }\end{array}$ & $\begin{array}{c}\text { Percentual } \\
\text { correspondente } \\
\text { (\%) }\end{array}$ \\
\hline \multirow{7}{*}{ 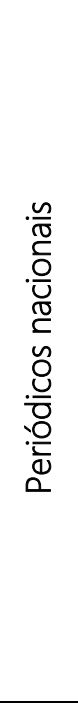 } & Ciência \& Educação & 535 & 9 & 1,68 \\
\hline & $\begin{array}{l}\text { Ensaio Pesquisa em } \\
\text { Educação em Ciências }\end{array}$ & 314 & 7 & 2,23 \\
\hline & $\begin{array}{c}\text { Amazônia - Revista de } \\
\text { Educação em Ciências e } \\
\text { Matemáticas }\end{array}$ & 130 & 4 & 3,08 \\
\hline & $\begin{array}{c}\text { Investigações em Ensino } \\
\text { de Ciências }\end{array}$ & 296 & 8 & 2,70 \\
\hline & $\begin{array}{l}\text { Revista Brasileira de } \\
\text { Pesquisa em Educação } \\
\text { em Ciências }\end{array}$ & 285 & 8 & 2,81 \\
\hline & Revista Acta Scientiae & 320 & 3 & 0,94 \\
\hline & Total & - & 39 & - \\
\hline \multirow{4}{*}{ 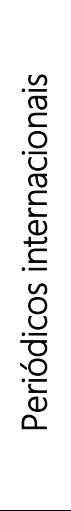 } & $\begin{array}{c}\text { Enseñanza de las } \\
\text { Ciencias }\end{array}$ & 431 & 13 & 3,02 \\
\hline & $\begin{array}{c}\text { Revista Eureka sobre } \\
\text { Enseñanza y Divulgación } \\
\text { de las Ciencias }\end{array}$ & 514 & 5 & 0,97 \\
\hline & $\begin{array}{l}\text { Revista Electrónica de } \\
\text { Enseñanza de las } \\
\text { Ciencias }\end{array}$ & 359 & 7 & 1,95 \\
\hline & $\begin{array}{l}\text { Revista Electrónica de } \\
\text { Investigación en }\end{array}$ & 129 & 4 & 3,10 \\
\hline
\end{tabular}




\begin{tabular}{l|c|c|c|c}
\hline \multirow{2}{*}{} & Educación en Ciencias & & & \\
\cline { 2 - 5 } & Total & - & 29 & - \\
\hline
\end{tabular}

A Figura 1 apresenta o número de publicações nacionais encontradas a cada ano de investigação desta pesquisa bibliográfica, bem como especifica a quantidade e quais os periódicos que publicaram por ano.

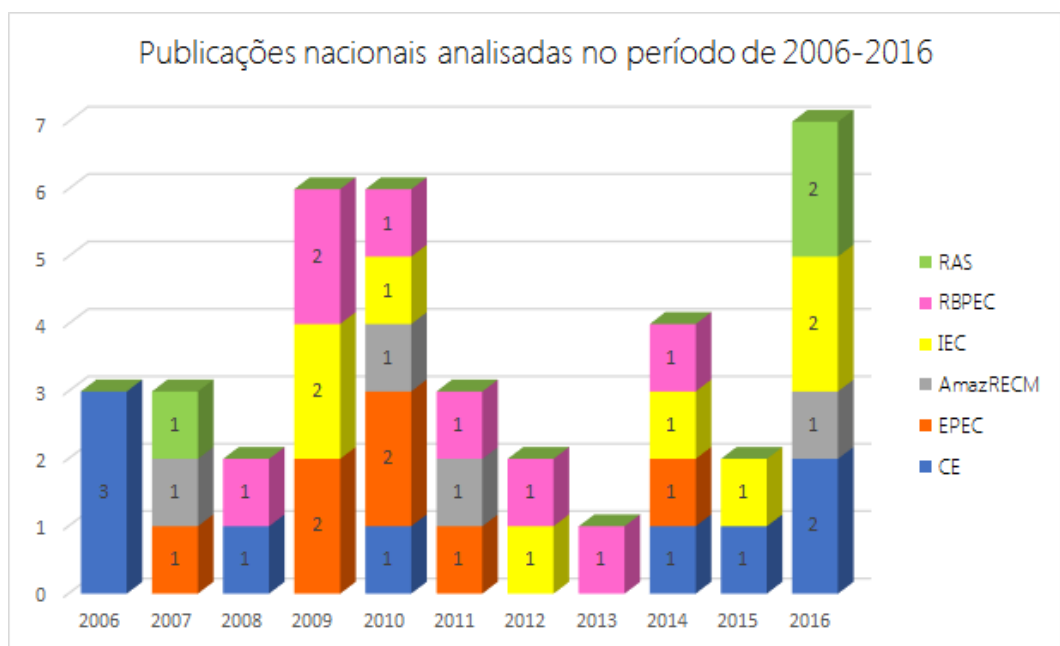

Figura 1 - Número de publicações nacionais selecionadas para análise em cada ano

Ressaltamos que no ano de 2016 encontramos um maior número de artigos para análise (7 artigos no total, publicados em quatro dos seis periódicos selecionados), seguido dos anos 2009 e 2010, com 6 publicações anuais. Como é possível constatar na Figura 1, foram encontrados poucos artigos nos outros anos que compreendem o período de busca realizada nos periódicos. A Figura 2 apresenta as publicações internacionais selecionadas para análise em cada um dos anos que compreende a nossa pesquisa bibliográfica.

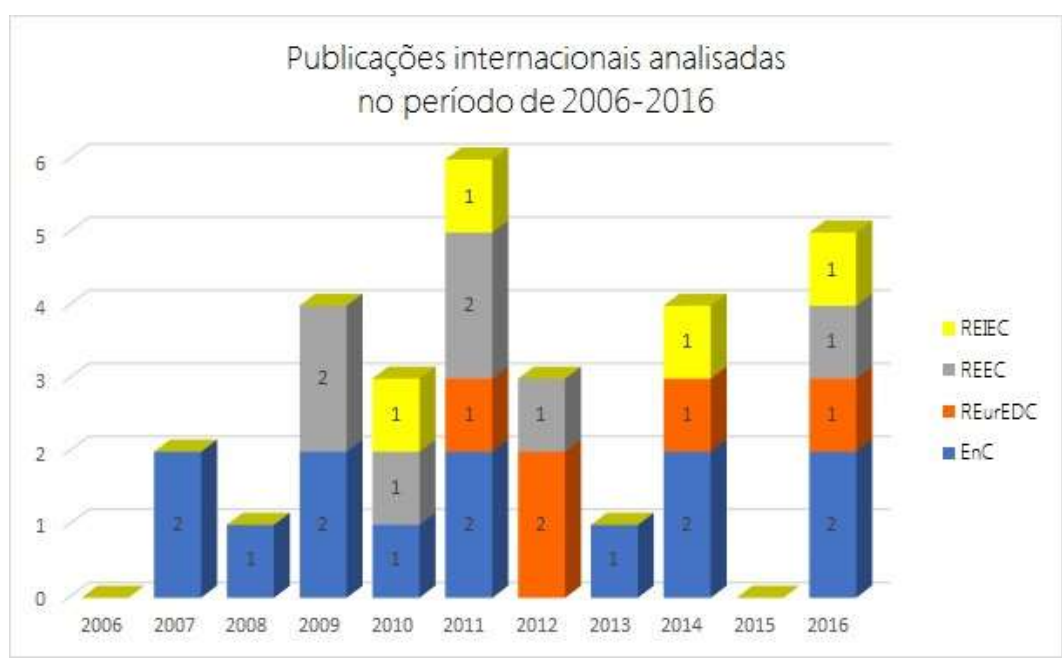

Figura 2 - Número de publicações internacionais selecionadas para análise em cada ano

Conforme evidenciado na Figura 2, não foram encontrados artigos para análise nos anos de 2006 e 2015. Já no ano de 2011 e 2016 foram selecionados, respectivamente, 6 e 5 artigos relacionados com a formação continuada de professores de Ciências, publicados nos quatro periódicos analisados. Ressaltamos que, dos 11 anos analisados, o periódico 
Enseñanza de las Ciências só não apresentou publicações de nosso interesse nos anos de 2006, 2012 e 2015.

\section{6) Leitura do material}

Para a leitura do material selecionado, Gil (2002, p. 77) sugere que a análise na pesquisa bibliográfica deve contemplar os seguintes objetivos: "a) identificar as informações e os dados constantes do material; b) estabelecer relações entre as informações e os dados obtidos com o problema proposto; c) analisar a consistência das informações e dados apresentados pelos autores".

A sistematização da leitura do material bibliográfico selecionado na etapa anterior ocorreu da seguinte maneira: $1^{a}$ etapa: leitura exploratória, a qual tem por objetivo verificar se os artigos selecionados interessam para a pesquisa realizada. Esta leitura permite que se tenha uma visão geral do todo, o que possibilita uma melhor compreensão do material. Neste momento foram analisados o título, resumo e palavras-chave; $2^{a}$ etapa: leitura analítica, em que é realizada a leitura integral dos artigos selecionados para análise, assim como a identificação e sistematização das ideias; $3^{a}$ etapa: leitura interpretativa, é caracterizada como o momento mais complexo, pois é necessário relacionar as ideias expressas nos materiais analisados com o problema para o qual se busca resposta. Nesta terceira etapa, caracterizada pela síntese das ideias, são selecionadas as partes essenciais do texto, o que consiste em "recompor o todo decomposto pela análise", conforme descrito por Gil (2002, p. 79).

Tabela 2 - Categorias emergentes e número de publicações em cada uma delas

\begin{tabular}{cc} 
Categorias & Número de artigos \\
\hline Práticas formativas e reflexivas & 16 \\
Conhecimento científico & 12 \\
Interação universidade-escola & 11 \\
Currículo & 11 \\
Metodologias de ensino & 10 \\
TIC & 5 \\
Contextualização & 2 \\
Outros & 1 \\
\hline Total & 68 \\
\hline
\end{tabular}

Após a realização da leitura dos artigos selecionados para esta pesquisa bibliográfica, foi possível observar que alguns apresentavam semelhanças quanto ao assunto abordado nos cursos de formação continuada de professores de Ciências. Desta maneira, como forma de organização do material, bem como para facilitar o entendimento dos artigos, foram elaboradas oito categorias emergentes que estão apresentadas na Tabela 2, juntamente com o número de publicações agrupadas em cada uma delas. 
A seguir estão descritas cada uma das categorias elaboradas a partir da leitura do material bibliográfico:

Práticas formativas e reflexivas: Os artigos que fazem parte desta categoria estão voltados para o debate e reflexão nos cursos de formação continuada sobre a formação docente, por meio do desenvolvimento de pesquisas colaborativas. Também são abordados assuntos relacionados à prática reflexiva, bem como o papel do formador para auxiliar nesta reflexão.

Conhecimento científico: Fazem parte desta categoria os trabalhos que visam o aprimoramento do conhecimento do conteúdo das disciplinas que compõe a área de Ciências, sendo elas Química, Física e Biologia, bem como artigos voltados para discussões sobre a natureza do conhecimento científico.

Interação universidade-escola: os artigos que compõe esta categoria estão relacionados a cursos de formação continuada voltados aos professores de Ciências da educação básica, os quais são organizados por sujeitos vinculados aos programas de extensão de instituições superiores, programas de iniciação a docência como o Programa Institucional de Bolsas de Iniciação à Docência (PIBID), ou ainda relacionados aos trabalhos de conclusão de curso e estágios supervisionados, no caso dos cursos de licenciatura.

Currículo: Os trabalhos selecionados foram desenvolvidos em cursos de formação continuada com foco no currículo escolar, como discussões sobre o Ensino de Química voltado para a Educação de Jovens e Adultos, a elaboração de materiais instrucionais que abordam aspectos da Ciência, Tecnologia, Sociedade e Ambiente (CTSA), assim como discussões sobre as políticas educacionais as quais possuem uma grande influência na organização do currículo escolar.

Metodologias de ensino: Os artigos que fazem parte desta categoria têm como foco trabalhar com os professores participantes do curso de formação continuada diferentes metodologias de ensino que podem ser utilizadas em sala de aula, como as sequências didáticas, resolução de problemas e estudo de casos.

Tecnologias da Informação e comunicação: As publicações selecionadas referem-se a atividades voltadas para a elaboração e uso de diferentes tecnologias que podem ser utilizadas no âmbito escolar como, por exemplo, o uso do laboratório de informática, a construção de simulações em cursos voltados para professores de química da educação básica, assim como a realização de programas de formação continuada de forma online.

Contextualização: Fazem parte desta categoria os artigos que apresentam como embasamento teórico a contextualização no ensino de Química.

Outros: $\bigcirc$ trabalho pertencente a esta categoria não apresentou semelhança com as categorias anteriores, pois relata formações continuadas de professores em museus de ciências.

\section{7) Fichamento}

A partir da leitura dos artigos apresentados na seção anterior, surgiram as seguintes categorias para análise: a) Quanto à abrangência dos cursos de formação; b) Tipo de formação de professores; c) Nível de atuação dos professores; d) Tempo de duração dos cursos de formação. No Quadro 2, para cada uma dessas categorias, são apresentadas as subcategorias de análise e o número de artigos que corresponde a cada uma delas. 
Quadro 2 - Análise das publicações relacionadas à cursos de formação continuada de professores de Ciências

\begin{tabular}{|c|c|c|}
\hline Categorias & Subcategorias & Número de artigos \\
\hline \multirow{2}{*}{$\begin{array}{c}\text { A) abrangência dos cursos de } \\
\text { formação }\end{array}$} & Química & 13 \\
& Física & 5 \\
& Biologia & 14 \\
& Ciências (ensino fundamental) & 13 \\
\hline $\begin{array}{c}\text { B) Tipo de formação de } \\
\text { professores }\end{array}$ & Outras Relações & 16 \\
\hline $\begin{array}{c}\text { C) Nível de atuação dos } \\
\text { professores }\end{array}$ & Formação inicial e continuada & 51 \\
& Fundamental & 17 \\
\hline $\begin{array}{c}\text { Cursos de formação. } \\
\text { Dempo de duração dos }\end{array}$ & Médio & 33 \\
\hline
\end{tabular}

Quanto à abrangência dos cursos de formação, categoria A, percebemos um maior número de publicações relativas aos cursos de formação continuada para professores de Química se comparado aos de Física e Biologia, respectivamente. Também foi expressivo o número de trabalhos direcionados para a formação de professores de Ciências do Ensino Fundamental. Na etapa 9 será realizada uma análise dos 13 artigos relacionados à cursos de formação de professores para a área de Ciências da Natureza, mencionados no Quadro 2. Para a subcategoria "outras relações", as publicações trazem diversas associações das áreas e/ou disciplinas, tais como: Ciências e Biologia; Ciências e Química; Química e Física; assim como cursos de formação voltados para todos os professores da escola.

Relacionado ao tipo de formação de professores, 51 artigos realizaram exclusivamente cursos de formação continuada e 17 referem-se a formação inicial e continuada de professores, sendo estes, na sua grande maioria, promovidos por instituições de ensino superior, em que há um engajamento de formadores de professores e acadêmicos.

A categoria C especifica o número de artigos que desenvolvem cursos de formação para os professores atuantes em nível fundamental, médio ou em ambos. Foi possível perceber uma maior quantidade de trabalhos voltados aos professores atuantes no Ensino Médio, seguido dos trabalhos que realizaram cursos de formação para professores atuantes no ensino fundamental. Para a categoria $D$, os artigos foram classificados quanto ao período 
de realização dos cursos. Caracterizamos como cursos de curta duração aqueles que foram realizados em um período de até 3 meses. Cursos de média duração que compreendem o período de 6 a 12 meses. Já os cursos de longa duração são aqueles que possuem um tempo de realização acima de um ano. Desta forma, fica evidente que o número de artigos encontrados que descrevem atividades de formação continuada de curta e longa duração foram semelhantes. Fazem parte da opção "não se aplica", os trabalhos que buscaram investigar de um modo geral como estão sendo desenvolvidos os cursos de formação continuada de professores.

\section{8) Organização lógica do assunto}

Das 68 publicações mencionadas anteriormente, apenas 13 relatam trabalhos de formação continuada para professores pertencentes à área de Ciências da Natureza e suas Tecnologias da educação básica. No anexo 1 estão apresentados os treze artigos selecionados, bem como evidenciado o tipo de formação, o tempo de duração dos cursos e a categoria que corresponde cada trabalho.

\section{9) Redação do texto}

A partir dos resultados obtidos por meio da realização da pesquisa bibliográfica apresentada anteriormente, iremos apresentar as considerações finais sobre os seguintes apontamentos:

I. docentes participantes dos cursos de formação;

II. temas abordados nos processos formativos;

III. duração dos cursos de formação continuada.

Para o primeiro apontamento, ao analisarmos os dados apresentados na Tabela 1 fica evidente o reduzido número de publicações que relatam cursos de formação continuada de professores de Ciências. Dentre as 6 revistas nacionais analisadas no período de 2006 a 2016, o maior percentual correspondente obtido a partir do total de publicações foi de 3,08\%, os quais referem-se às publicações na Amazônia - Revista de Educação em Ciências e Matemáticas.

As análises realizadas nas 4 revistas internacionais evidenciaram um percentual correspondente de 3,10\% referente aos artigos publicados na Revista Electrónica de Investigación en Educación en Ciencias. A partir destas constatações reforçamos a necessidade de serem implementados cursos de formação continuada voltados aos professores de Ciências atuantes na rede básica de ensino, visto a carência desse tipo de atividade a esses docentes.

o segundo apontamento refere-se aos diferentes temas que foram abordados nos cursos de formação continuada relatados nos artigos. Das 68 publicações emergiram 8 categorias relacionadas ao conteúdo abordado nos processos formativos. Dentre as categorias de análise, houve uma predominância de artigos voltados para o estudo de "práticas formativas e reflexivas" e "conhecimento científico", conforme evidenciado na Tabela 2.

Contrastando com esses dados, dos treze artigos selecionados para análise (etapa 8), os quais relatavam cursos de formação continuada de professores pertencentes à área de Ciências da Natureza (incluindo os docentes de Química, Física e Biologia), evidenciamos apenas uma publicação relacionada a categoria de análise "práticas formativas e reflexivas" 
(ANEXO 1). Acreditamos que o pouco enfoque dado a estas questões pode estar associado ao tempo de duração dos cursos de formação continuada, pois para que haja uma reflexão docente deve ser proporcionado um número maior de encontros que estimulem as discussões e reflexões entre o grupo de professores, bem como a análise pessoal da prática docente.

Dos 68 artigos analisados constatamos uma predominância de publicações que relatam cursos de formação continuada realizados em um período de curta ou de longa duração. Já na análise dos 13 artigos apresentados no Anexo 1, evidenciamos um maior número de cursos desenvolvidos em um curto período de tempo. Uma hipótese para a escolha desse tipo de formação continuada deve-se a carga horária excessiva de trabalho dos professores, o que pode inviabilizar a sua participação em atividade de média ou longa duração.

Com base neste levantamento bibliográfico realizado, ficou explícita a necessidade de serem desenvolvidos cursos de formação continuada que abordem as práticas formativas e reflexivas, especialmente aos professores de Ciências da rede básica de ensino. A partir desta constatação, os autores deste trabalho realizaram um curso de formação continuada voltado a esses docentes, sendo propiciado desde o primeiro encontro momentos para a reflexão docente (ROCHA, 2018). Além disso, foram trabalhados alguns temas de interesse dos professores, como currículo, metodologias de ensino e contextualização, o que vai ao encontro das categorias emergentes apontadas neste trabalho.

Enfatizamos a necessidade de serem realizados cursos de desenvolvimento profissional docente, especialmente para os professores da rede básica de ensino, visto a carência deste tipo de formação que oportunize momentos de reflexão docente e da prática pedagógica, estimulando a autonomia e autoria do professor na elaboração de suas atividades, com vistas à melhoria da qualidade do ensino.

\section{Agradecimento}

Ao apoio financeiro CAPES.

\section{Referências bibliográficas}

ANDRÉ, M. Formação de professores: a constituição de um campo de estudos. Educação, v. 33, n. 3, p. 174-181, 2010.

ASTUDILLO, C.; RIVAROSA, A.; ORTIZA, F. Formas de pensar lá enseñanza en ciencias. Un análisis de secuencias didácticas. Revista Electrónica de Enseñanza de las Ciencias, v. 10, n. 3, p. 567-586, 2012.

BOGDAN, R. C.; BIKLEN, S. K. Investigação qualitativa em educação. Porto: Porto Editora, 1994.

BRASIL. (2000). Parâmetros Curriculares Nacionais para o Ensino Médio. Brasília. 2000. Disponível em: http://portal.mec.gov.br/seb/arquivos/pdf/ciencian.pdf. Acesso em: 14 out. 2020.

BRASIL. Ministério da Educação, Secretaria de Educação básica. Orientações Curriculares para o Ensino Médio: Ciências da Natureza, Matemática e suas Tecnologias. Orientações Curriculares para o Ensino Médio. Brasília, 2006, v. 2, 135 p. 
BRASIL. Conselho Nacional de Educação. Define as Diretrizes Curriculares Nacionais para a formação inicial em nível superior (cursos de licenciatura, cursos de formação pedagógica para graduados e cursos de segunda licenciatura) e para a formação continuada. Resolução CNE/CP n. 02/2015, de $1^{0}$ de julho de 2015. Brasília, Diário Oficial [da] República Federativa do Brasil, seção 1, n. 124, p. 8-12, 02 de julho de 2015. Disponível em: http://portal.mec.gov.br/index.php?option=com_docman\&view=download\&alias=121201rcp002-15\&category_slug=agosto-2019-pdf\&ltemid=30192. Acesso em: 14 out. 2020.

COBOS, T. L.; GÁMEZ, C. M. Desarrollo profesional docente de profesorado de secundaria en una experiencia de innovación mediante investigaciones escolares. Revista Eureka sobre Enseñanza y Divulgación de las Ciencias, v. 13, n. 3, p. 686-704, 2016.

COUSO, D.; PINTÓ, R. Análisis del contenido del discurso cooperativo de los profesores de ciencias en contextos de innovación didáctica. Enseñanza de las Ciencias: Revista de investigación y experiencias didácticas, v. 27, n. 1, p. 5-18, 2009.

ECHEVERRÍA, A. R.; BELISÁRIO, C. M. Formação inicial e continuada de professores num núcleo de pesquisa em ensino de ciências. Revista Brasileira de Pesquisa em Educação em Ciências, v. 8, n. 3, p. 1-21, 2008.

FORMOSINHO, J. Formação de professores: Aprendizagem profissional e acção docente. Porto: Porto Editora, 2009.

GIL, A. C. Como elaborar projetos de pesquisa. São Paulo: Editora Atlas S. A., 2002.

GÜNTHER, H. Pesquisa Qualitativa Versus Pesquisa Quantitativa: Esta é a Questão?. Revista Psicologia: Teoria e Pesquisa, v. 22, n. 2, p. 201-210, 2006.

JACOBUCCI, D. F. C. Contribuições dos espaços não-formais de educação para a formação da cultura científica. Revista em Extensão, v. 7, p. 55-66, 2008.

JACOBUCCl, D. F. C.; JACOBUCCl, G. B.; NETO, J. M. Experiências de formação de professores em centros e museus de ciências no Brasil. Revista Electrónica de Enseñanza de las Ciencias, v. 8, n. 1, p. 118-136, 2009.

MANFREDO, E. C. G.; GONÇALVES, T. O. Saberes nas histórias de vida e na prática de formadores de professores. Amazônia: Revista de Educação em Ciências e Matemáticas, v. 16, n. 36, p. 190-205, 2020.

MARBÀ-TALLADA, A.; GAIRÍN, J.; TALAVER, M. (2013). Evaluación del conocimiento didáctico y científico del profesorado: el caso del sistema educativo de Panamá. Enseñanza de las Ciencias: Revista de investigación y experiencias didácticas, v. 31, n. 3, p. 229-247, 2013.

MARCELO, C. Desenvolvimento profissional docente: passado e futuro. Revista de Ciências da Educação, n. 8, p. 7-22, jan/abr. 2009.

MARZÁBAL, A.; MERINO, C.; ROCHA, A. (2014). El obstáculo epistemológico como objeto de reflexión para la activación del cambio didáctico en docentes de ciencias en ejercicio. Revista Electrónica de Investigación en Educación en Ciencias, v. 9, n. 1, p. 70-83, 2014.

NÓVOA, A. Formação de professores e profissão docente. In: NÓVOA, A. Os professores e a sua formação. Lisboa: Dom Quixote, 1992, p. 13-33.

OLIVA, J. M. Dificultades para la implicación del profesorado de Educación Secundaria en la lectura, innovación e investigación en didáctica de las ciencias (I): el problema de la 
inmersión. Revista Eureka sobre Enseñanza y Divulgación de las Ciencias, v. 8, n. 1, p. 41-53, 2011.

OLIVA, J. M. Dificultades para la implicación del profesorado de Secundaria en la lectura, innovación e investigación en didáctica de las ciencias (II): el problema del "manos a la obra". Revista Eureka sobre Enseñanza y Divulgación de las Ciencias, v. 9, n. 2, p. 241-251, 2012.

PEREIRA, L. L. S.; BENITE, A. M. C. Redes sociais como espaço de interações sobre formação de professores de ciências para a educação inclusiva. Revista Investigações em Ensino de Ciências, v. 17, n. 3, p. 615-639, 2012.

ROCHA, T. R. Módulo Temático: contribuição para a formação continuada de professores de Ciências. 2018. 295 p. Tese (Doutorado em Educação em Ciências)-Universidade Federal de Santa Maria, Santa Maria, RS, 2018.

SCHNEIDER, E. M.; MEGLHIORATTI, F. A.; CORAZZA, M. J. Discursos de professores em formação continuada acerca da relação entre a manipulação genética e a possibilidade de melhoramento em humanos. Revista Ciência \& Educação, v. 22, n. 3, p. 597-613, 2016.

SILVA, P. S. A.; CHAVES, S. N. Epistemologia, ética e política na formação de professores de ciências. Revista Ensaio, v. 11, n. 2, p. 259-276, 2009.

TARDIF, M. Saberes docentes e formação profissional. Rio de Janeiro: Vozes, 2014.

VILELA-RIBEIRO, E. B.; BENITE, A. M. C. Concepções sobre natureza da ciência e ensino de ciências: um estudo das interações discursivas em um Núcleo de Pesquisa em Ensino de Ciências. Revista Brasileira de Pesquisa em Educação em Ciências, v. 9, n. 1, p. 1-23, 2009. 
Anexo 1 - Artigos selecionados na pesquisa sobre cursos de formação continuada para professores de Ciências da educação básica

\begin{tabular}{|c|c|c|c|}
\hline $\begin{array}{l}\text { Periódico e } \\
\text { ano de } \\
\text { publicação }\end{array}$ & Título & Autores & $\begin{array}{l}\text { Tipo de formação - } \\
\text { Tempo de duração } \\
\text { - Categoria }\end{array}$ \\
\hline $\begin{array}{l}\text { RBPEC } \\
(2008)\end{array}$ & $\begin{array}{l}\text { Formação inicial e continuada de } \\
\text { professores num núcleo de pesquisa } \\
\text { em ensino de ciências }\end{array}$ & $\begin{array}{l}\text { ECHEVERRÍA, A. } \\
\text { R.; BELISÁRIO, C. } \\
\text { M. }\end{array}$ & $\begin{array}{c}\text { FIC - LDU } \\
\text { Interação universidade- } \\
\text { escola }\end{array}$ \\
\hline $\begin{array}{l}\text { RBPEC } \\
(2009)\end{array}$ & $\begin{array}{c}\text { Concepções sobre natureza da } \\
\text { ciência e ensino de ciências: um } \\
\text { estudo das interações discursivas em } \\
\text { um Núcleo de Pesquisa em Ensino de } \\
\text { Ciências }\end{array}$ & $\begin{array}{l}\text { VILELA-RIBEIRO, } \\
\text { E. B.; BENITE, A. } \\
\text { M. C. }\end{array}$ & $\begin{array}{c}\text { FIC - CDU } \\
\text { Interação universidade- } \\
\text { escola }\end{array}$ \\
\hline $\begin{array}{l}\text { REEC } \\
(2009)\end{array}$ & $\begin{array}{l}\text { Experiências de formação de } \\
\text { professores em centros e museus de } \\
\text { ciências no Brasil }\end{array}$ & $\begin{array}{l}\text { JACOBUCCI, D. F. } \\
\text { C.; JACOBUCCI, } \\
\text { G. B.; NETO, J. M. }\end{array}$ & $\begin{array}{l}\text { FC - CDU } \\
\text { Outros }\end{array}$ \\
\hline $\begin{array}{l}\text { EPEC } \\
(2009)\end{array}$ & $\begin{array}{l}\text { Epistemologia, ética e política na } \\
\text { formação de professores de ciências }\end{array}$ & $\begin{array}{l}\text { SILVA, P. S. A.; } \\
\text { CHAVES, S. N. }\end{array}$ & $\begin{array}{l}\text { FC - CDU } \\
\text { Currículo }\end{array}$ \\
\hline $\begin{array}{c}\text { EnC } \\
(2009)\end{array}$ & $\begin{array}{c}\text { Análisis del contenido del discurso } \\
\text { cooperativo de los profesores de } \\
\text { ciencias en contextos de innovación } \\
\text { didáctica }\end{array}$ & $\begin{array}{l}\text { COUSO, D.; } \\
\text { PINTÓ, R. }\end{array}$ & $\begin{array}{c}\text { FC - LDU } \\
\text { Metodologias de ensino }\end{array}$ \\
\hline $\begin{array}{l}\text { REEC } \\
(2011)\end{array}$ & $\begin{array}{c}\text { Formas de pensar la enseñanza en } \\
\text { ciencias. Un análisis de secuencias } \\
\text { didácticas }\end{array}$ & $\begin{array}{l}\text { ASTUDILLO, C:; } \\
\text { RIVAROSA, A.; } \\
\text { ORTIZA, F. }\end{array}$ & $\begin{array}{c}\text { FIC - MDU } \\
\text { Metodologias de ensino }\end{array}$ \\
\hline $\begin{array}{l}\text { REur } \\
\text { EDC } \\
\text { (2011) }\end{array}$ & $\begin{array}{c}\text { Dificultades para la implicación del } \\
\text { profesorado de Educación Secundaria } \\
\text { en la lectura, innovación e } \\
\text { investigación en didáctica de las } \\
\text { ciencias (I): el problema de la } \\
\text { inmersión }\end{array}$ & OLIVA, J. M. & $\begin{array}{l}\text { FC - LDU } \\
\text { Currículo }\end{array}$ \\
\hline $\begin{array}{l}\text { REur } \\
\text { EDC } \\
(2012)\end{array}$ & $\begin{array}{l}\text { Dificultades para la implicación del } \\
\text { profesorado de Secundaria en la } \\
\text { lectura, innovación e investigación en } \\
\text { didáctica de las ciencias (II): el } \\
\text { problema del "manos a la obra" }\end{array}$ & OLIVA, J. M. & $\begin{array}{l}\text { FC - LDU } \\
\text { Currículo }\end{array}$ \\
\hline $\begin{array}{l}\text { IEC } \\
(2012)\end{array}$ & $\begin{array}{l}\text { Redes sociais como espaço de } \\
\text { interações sobre formação de } \\
\text { professores de ciências para a } \\
\text { educação inclusiva }\end{array}$ & $\begin{array}{l}\text { PEREIRA, L. L. S.; } \\
\text { BENITE, A. M. C. }\end{array}$ & $\begin{array}{c}\text { FIC - MDU } \\
\text { Interação universidade- } \\
\text { Escola }\end{array}$ \\
\hline
\end{tabular}

